\title{
A simple method to remove an embedded self-expandable metallic stent with a balloon
}

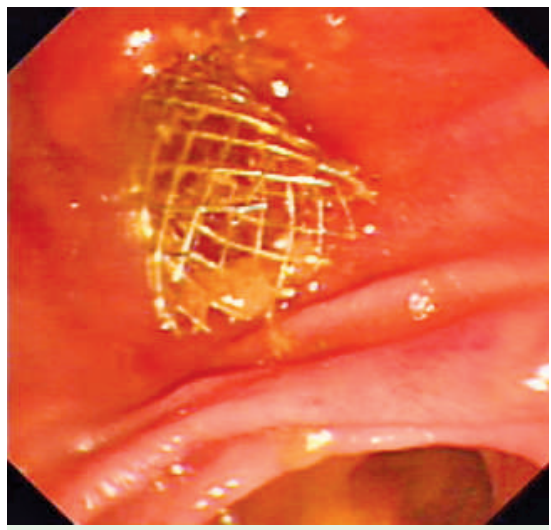

Fig. 1 A covered self-expandable metallic Wallstent was placed into the common bile duct.

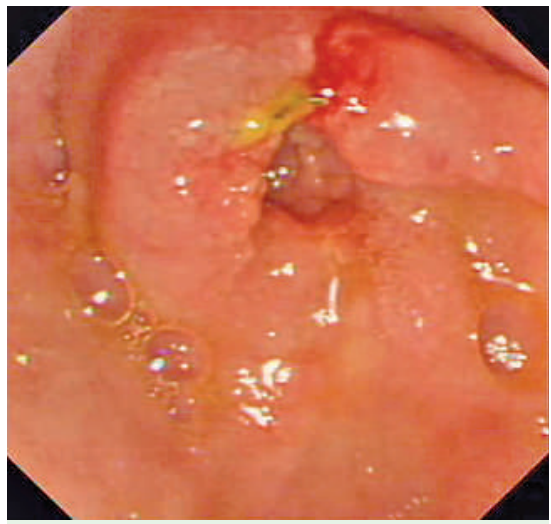

Fig. 2 After 4 months, the self-expandable metallic stent migrated into the common bile duct, and attempts to remove it with a snare and rat-tooth forceps were unsuccessful.

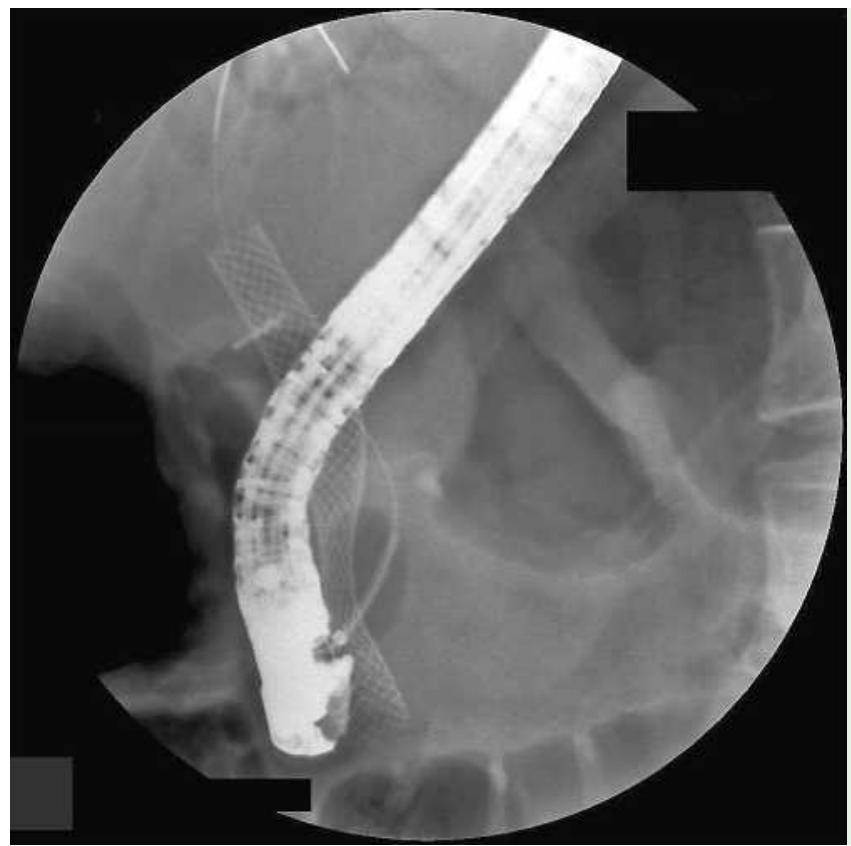

Fig. 3 A guide wire was inserted into the interstice between the self-expandable metallic stent and bile ductal wall, followed by a balloon, which was then dilated.

A 56-year-old woman with a history of obstructive jaundice secondary to a postoperative biliary injury after a laparoscopic cholecystectomy was transferred to our hospital for treatment of a benign biliary stricture. She had three sessions of plastic biliary stent exchange $(8.5,10,11.5 \mathrm{Fr}, 9 \mathrm{~cm}$, Soehendra Tannenbaum stent; Wilson-Cook Medical Inc., Winston-Salem, North Carolina, USA) placed into the common bile duct (CBD) to treat biliary tract obstruction. Her liver function tests returned to normal. How- ever, after removal of the last plastic stent, the jaundice and right upper quadrant pain recurred. She then received a covered self-expandable metallic Wallstent (SEMS, Boston Scientific Corp., Natick, Massachusetts, USA) in the CBD ( $\bullet$ Fig. 1). She was asymptomatic after placement of the SEMS.

After 4 months, she was admitted for removal of the SEMS. Endoscopy showed that the SEMS had migrated and had embedded into the CBD ( $\bullet$ Fig. 2 ). Attempts to remove it with a snare and rat-tooth 

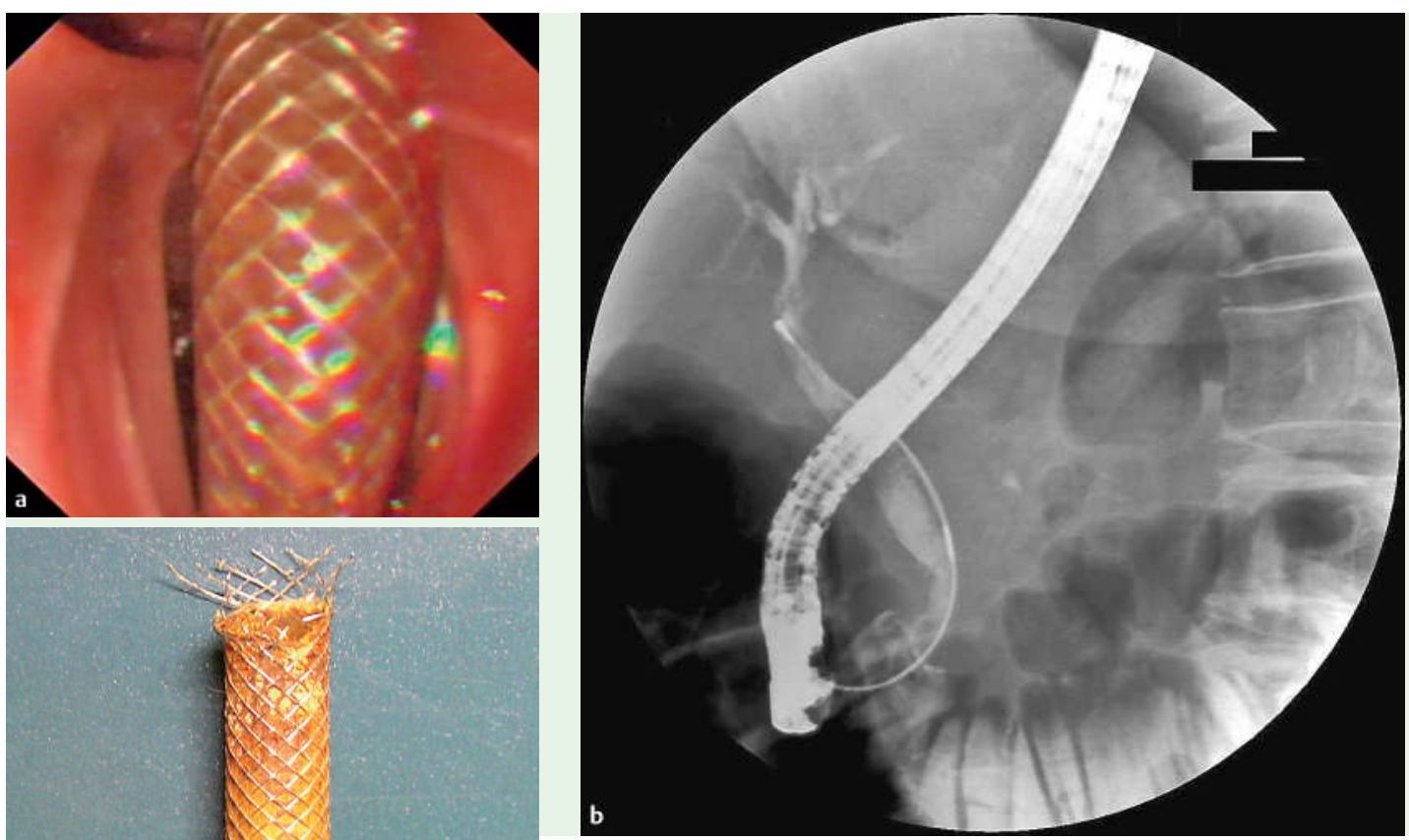

Fig. 4 a-c The self-expandable metallic stent was successfully captured and finally removed.

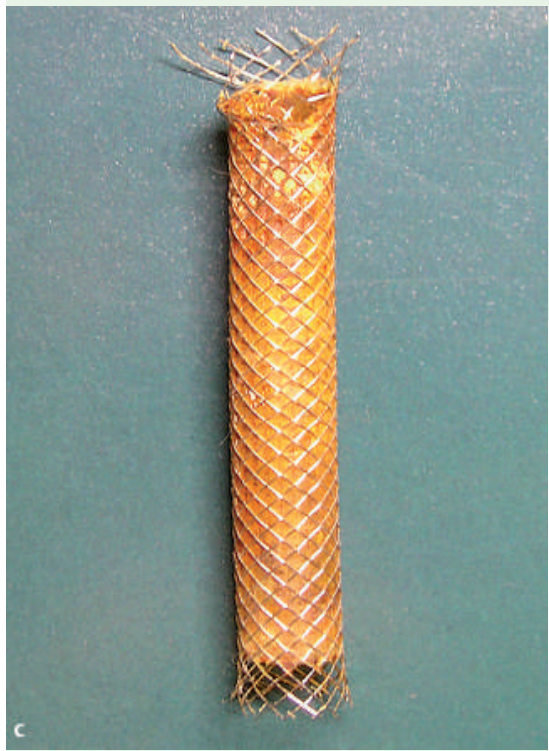

forceps were unsuccessful. Then a guide wire was inserted into the interstice between the SEMS and bile ductal wall, followed by a balloon, which was then dilated ( Fig. 3). The SEMS was gradually separated and dislodged from the CBD by balloon dilations, and the inferior segment of the SEMS was exposed ( $\nabla$ Fig. 4 a). Finally, the embedded SEMS was successfully captured with a snare and removed ( $\bullet$ Fig. 4 b, c).

\section{Z. S. Li, Z. Liao}

Department of Gastroenterology, Digestive Endoscopy Center, Changhai Hospital, Second Military Medical University, Shanghai, China

Dr. Zhuan Liao and Prof. Zharshen Li contributed equaly to this work

Bibliography

DOI 10.1055/s-2007-966582

Endoscopy 2007; 39: E233 -E234

(c) Georg Thieme Verlag KG Stuttgart · New York . ISSN 0013-726X

Corresponding author

\section{Z. S. Li, MD}

Department of Gastroenterology Changhai Hospital

Digestive Endoscopy Center

Second Military Medical University

174 Changhai Road

Shanghai, 200433

China

Fax: +86-21-55620081

zhaoshenli@hotmail.com 